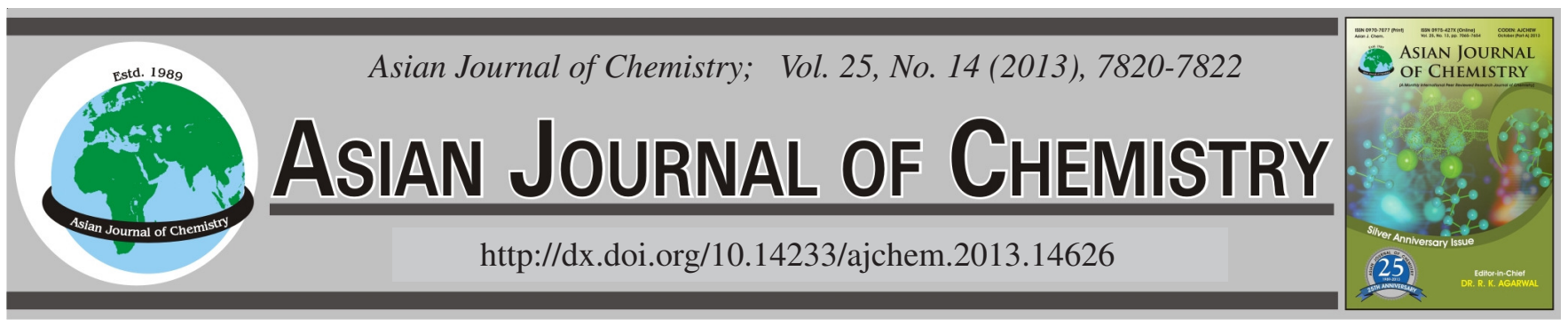

\title{
Synthesis, Crystal Structure and Bioactivity of $N$-(5-propyl-1,3,4-thiadiazol-2-yl)cyclopropanecarboxamide
}

\author{
Na-Bo Sun ${ }^{*}$, Jian-Zhong Jin, Chao Lei and Fang-Yue He
}

College of Biology and Environmental Engineering, Zhejiang Shuren University, Hangzhou 310015, Zhejiang Province, P.R. China

*Corresponding author: E-mail: nabosun@gmail.com

(Received: 28 September 2012;

Accepted: 18 July 2013)

AJC-13817

\begin{abstract}
A new 1,3,4-thiadiazole compound with m.f. $\mathrm{C}_{9} \mathrm{H}_{13} \mathrm{~N}_{3} \mathrm{OS}$, has been synthesized and confirmed by ${ }^{1} \mathrm{H}$ NMR and HRMS. The single crystal structure of the 1,3,4-thiadiazole compound was determined by a single crystal X-ray diffraction study. The crystal belongs to the triclinic system, space group P-1 with $\mathrm{a}=10.238(2), \mathrm{b}=10.325(2), \mathrm{c}=10.560(2) \AA, \alpha=104.09(3), \beta=109.50(3), \gamma=93.40(3)^{\circ}, \mathrm{Z}=4, \mathrm{~V}=$ 1008.4(3) $\AA^{3}, \mathrm{Mr}=211.28, \mathrm{Dc}=1.392 \mathrm{~g} / \mathrm{cm}^{3}, \mathrm{~S}=0.98, \mu=0.29 \mathrm{~mm}^{-1}, \mathrm{~F}(000)=448$, the final $\mathrm{R} 1=0.0970$ and $\mathrm{wR}^{2}=0.2147$ for 1776

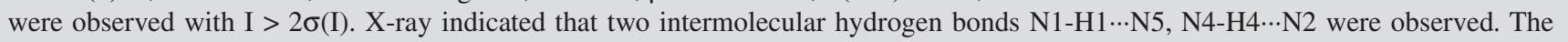
preliminary biological test shown that the synthesized compound has moderate herbicidal activity against Brassica campestris.
\end{abstract}

Key Words: Crystal structure, Synthesis, 1,3,4-thiadiazole, Herbicidal activity.

\section{INTRODUCTION}

Recent years, sulfur and nitro linked heterocycles has received considerable attentions in medicinal and pesticidal field ${ }^{1-6}$, due to their various applications. 1,3,4-Thiadiazoles had broad-spectrum biological activity which are widely applied in medicinal and agricultural applications. So synthesis of broader spectrum and highly bioactive 1,3,4-thiadiazole compounds becomes the hot spot in the agricultural and medicinal chemistry field. For example, many 1,3,4-thiadiazoles exhibit antibacterial activity ${ }^{7}$, anti-alzheimer activity ${ }^{8}$, fungicidal activity $^{9}$, anticancer activity ${ }^{10}$. Antimycobacterial activity ${ }^{11}$, nitrification Inhibitor ${ }^{12}$. Also 2-amino-5-substituted-1,3,4thiadiazoles are very useful starting materials for the synthesis of various bioactive molecules ${ }^{13-15}$. Many medicine or pesticide containing amide group and 1,3,4-thiadiazole moiety. On the other hand, cyclopropane is a active group in the drug design ${ }^{16-18}$. In view of these facts and also as a part of our work on the development of bioactive heterocyclic compounds, herein $N$ (5-propyl-1,3,4-thiadiazol-2-yl)cyclopropanecarboxamide was synthesized and its single crystal was also determined. The biological activity was determined.

\section{EXPERIMENTAL}

All the reagents are analytical grade. Melting points were determined using an X-4 apparatus and were uncorrected. ${ }^{1} \mathrm{H}$ NMR spectra were measured on a Bruker AC-P500 instrument (300 MHz) using TMS as an internal standard and $\mathrm{CDCl}_{3}$ as solvent. HRMS data was obtained on a FTICR-MS instrument (Ionspec 7.0T). Crystallographic data of the compound were collected on a rigaku saturn diffractometer.

Synthesis: The acid chloride was prepared according the reference ${ }^{13}$. Dropwise the acid chloride was added to 2-amino-5propyl-1,3,4-thiadiazole $(7.50 \mathrm{mmol})$, then vigorously stirred at ambient temperature for $4 \mathrm{~h}$. The corresponding amide 7 precipitated immediately. The product was filtered, washed with THF, dried and recrystallized from $\mathrm{EtOH}-\mathrm{H}_{2} \mathrm{O}$ to give the title compounds 7. White crystal, yield $84.5 \%$, m.p. 175$176{ }^{\circ} \mathrm{C} ;{ }^{1} \mathrm{H}$ NMR $\left(\mathrm{CDCl}_{3}\right) \delta: 1.02\left(\mathrm{t}, 3 \mathrm{H}, \mathrm{CH}_{3}\right), 1.05-1.21(\mathrm{~m}$, $4 \mathrm{H}$, cycloprane- $\left.\mathrm{CH}_{2}\right), 1.81\left(\mathrm{~m}, 2 \mathrm{H}, \mathrm{CH}_{2}\right), 2.25-2.31(\mathrm{~m}, 1 \mathrm{H}$, cycloprane-CH), 2.98 (t, 2H, $\mathrm{CH}_{2}$ ), 13.43 (s, 1H, NH); FTICRMS for $\mathrm{C}_{9} \mathrm{H}_{13} \mathrm{~N}_{3} \mathrm{OS}$ : found 210.0704, calcd. 210.0707.

Structure determination: The prism-shaped single crystal of the title compound was obtained by recrystallization from EtOH. The crystal with dimensions of $0.20 \mathrm{~mm} \times 0.16$ $\mathrm{mm} \times 0.12 \mathrm{~mm}$ was mounted on a Bruker SMART $1000 \mathrm{CCD}$ area-detector diffractometer with a graphite-monochromated MoK $\alpha$ radiation $(\lambda=0.71073 \AA)$ by using a Phi scan modes at $113(2) \mathrm{K}$ in the range of $2.06^{\circ} \leq \theta \leq 25.02^{\circ}$. A total of 7491 reflections were collected, of which 3544 were independent $\left(R_{\text {int }}=0.1576\right)$ and 1776 were observed with $\mathrm{I}>2 \sigma(\mathrm{I})$. The calculations were performed with SHELXS-97 program $^{19}$ and the empirical absorption corrections were applied to all intensity data. The non-hydrogen atoms were refined anisotropically. The hydrogen atoms were determined with theoretical calculations and refined isotropically. The final full-matrix least 
squares refinement gave $\mathrm{R} 1=0.0970$ and $\mathrm{wR} 2=0.2147(\mathrm{w}=$ $1 /\left[\sigma^{2}\left(\mathrm{~F}_{\mathrm{o}}^{2}\right)+(0.0901 \mathrm{P})^{2}\right]$ where $\left.\mathrm{P}=\left(\mathrm{F}_{\mathrm{o}}{ }^{2}+2 \mathrm{~F}_{\mathrm{c}}{ }^{2}\right) / 3\right), \mathrm{S}=0.98$,

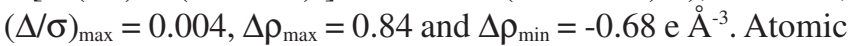
scattering factors and anomalous dispersion corrections were taken from International Table for X-ray crystallography ${ }^{20}$ A summary of the key crystallgraphic information were given in Table-1.

\begin{tabular}{ll}
\multicolumn{2}{c}{ TABLE-1 } \\
\multicolumn{2}{c}{ CRYSTAL DATA OF THE TITLE COMPOUND } \\
\hline Empirical Formula & $\mathrm{C}_{9} \mathrm{H}_{13} \mathrm{~N}_{3} \mathrm{OS}$ \\
Formula weight & 211.28 \\
$\mathrm{~T} / \mathrm{K}$ & $113(2)$ \\
$\lambda / \mathrm{nm}$ & 0.071073 \\
Crystal system, space group & Triclinic, $\mathrm{P}-1$ \\
Unit cell dimensions & $\mathrm{a}=10.238(2) \AA \alpha=104.09(3)^{\circ}$ \\
& $\mathrm{b}=10.325(2) \AA \beta=109.50(3)^{\circ}$ \\
& $\mathrm{c}=10.560(2) \AA \gamma=93.40(3)^{\circ}$ \\
V/nm ${ }^{3}$ & $1008.4(3) \AA^{3}$ \\
$Z$ & 4 \\
Calculated density $/\left(\mathrm{g}^{3} \mathrm{~cm}^{-3}\right)$ & $1.392 \mathrm{Mg} \mathrm{\textrm {m } ^ { - 3 }}$ \\
Absorption coefficient $\left(\mathrm{mm}^{-1}\right)$ & 0.292 \\
F(000) & 448 \\
Theta range for data collection & 2.06 to $25.02 \mathrm{deg}$ \\
Reflections collected / unique & $7491 / 3544\left[\mathrm{R}_{\text {int }}=0.1576\right]$ \\
Final $\mathrm{R}$ indices $[\mathrm{I}>2 \sigma(\mathrm{I})]$ & $\mathrm{R} 1=0.0970, \mathrm{wR} 2=0.2147$ \\
$\mathrm{R}$ indices (all data) & $\mathrm{R} 1=0.1511, \mathrm{wR} 2=0.2522$ \\
\hline
\end{tabular}

Biological activity: The herbicidal activities were determined according to the references.

\section{RESULTS AND DISCUSSION}

The cyclopropane-1,1-dicarboxylic acid, prepared from 1,2-dichlorethane and diethyl malonate was cyclized for $16 \mathrm{~h}$ at refluxing temperature. Microwave assistant irradiation was applied which shortened the reaction time to $40 \mathrm{~min}$. If the 1,2-dichlorethane changed to 1,2-dibromoethane, the reaction time is short. The cyclopropane-1,1-dicarboxylic acid was obtained from the hydrolysis of diethyl cyclopropane-1,1dicarboxylate, but the yield of this step is low, about $50 \%$. Cyclopropanecarbonyl chloride was prepared from the cyclopropane dicarboxylic acid and $\mathrm{SOCl}_{2}$, without isolation further reacted with 2-amino-5-propyl-1,3,4-thiadiazole at room temperature $^{13}$ (Scheme-I).

Herbicidal activities: The herbicidal activity results of the title compounds against Echinochloa crusgalli and Brassica campestris were determined. Its inhibition rates to

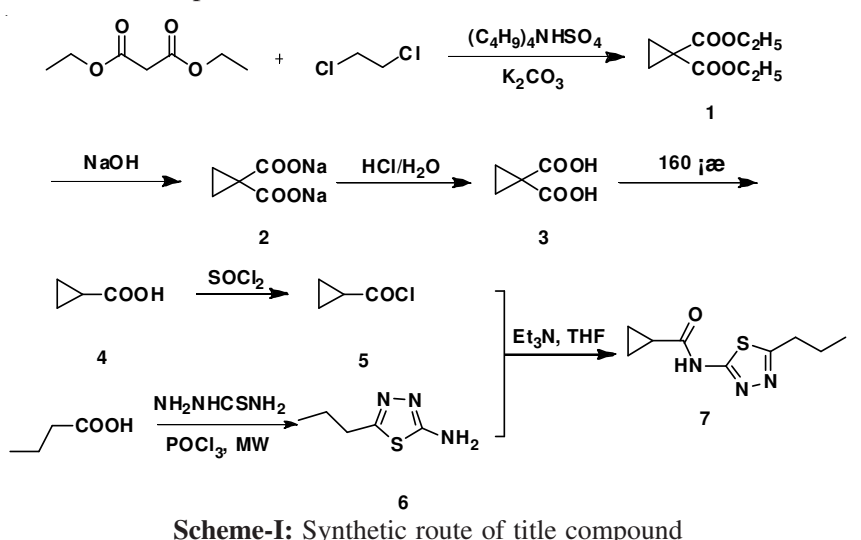

Scheme-I: Synthetic route of title compound
Echinochloa crusgalli and Brassica campestris reach $6.2 \%$, $38.4 \%$ at $50 \mu \mathrm{g} / \mathrm{mL}$ and $0 \%, 34.8 \%$ at $10 \mathrm{~g} / \mathrm{mL}$ respectively. The title compounds exhibit moderate herbicidal activities against Brassica campestris at 100 ppm. On the other hand, the title compounds exhibit no herbicidal activity against Echinochloa crusgalli.

Crystal structure: The selected bond lengths and bond angles are given in Table-2. The molecular structure of the title compound is shown in Fig. 1. The molecular packing of the molecule is shown in Fig. 2.

\section{TABLE-2}

SELECTED BOND LENGTHS (Å) AND BOND ANGLES $\left({ }^{\circ}\right)$

\begin{tabular}{cccc}
\hline Bond & Dist. & Angle & $\left({ }^{\circ}\right)$ \\
\hline $\mathrm{S}(1)-\mathrm{C}(5)$ & $1.723(5)$ & $\mathrm{C}(5)-\mathrm{S}(1)-\mathrm{C}(6)$ & $86.4(2)$ \\
$\mathrm{S}(2)-\mathrm{C}(14)$ & $1.728(5)$ & $\mathrm{C}(4)-\mathrm{N}(1)-\mathrm{C}(5)$ & $123.7(4)$ \\
$\mathrm{N}(1)-\mathrm{C}(4)$ & $1.356(6)$ & $\mathrm{C}(5)-\mathrm{N}(2)-\mathrm{N}(3)$ & $112.7(4)$ \\
$\mathrm{N}(2)-\mathrm{N}(3)$ & $1.401(5)$ & $\mathrm{C}(14)-\mathrm{N}(5)-\mathrm{N}(6)$ & $112.9(4)$ \\
$\mathrm{N}(4)-\mathrm{C}(14)$ & $1.379(6)$ & $\mathrm{C}(2)-\mathrm{C}(1)-\mathrm{C}(3)$ & $60.3(3)$ \\
$\mathrm{N}(5)-\mathrm{N}(6)$ & $1.388(5)$ & $\mathrm{O}(1)-\mathrm{C}(4)-\mathrm{N}(1)$ & $121.3(4)$ \\
\hline
\end{tabular}

Symmetry transformation: a: $x, y+1, z ; \mathrm{b}:-x, y,-z+1 / 2 ; \mathrm{c}:-x,-y+1,-z$

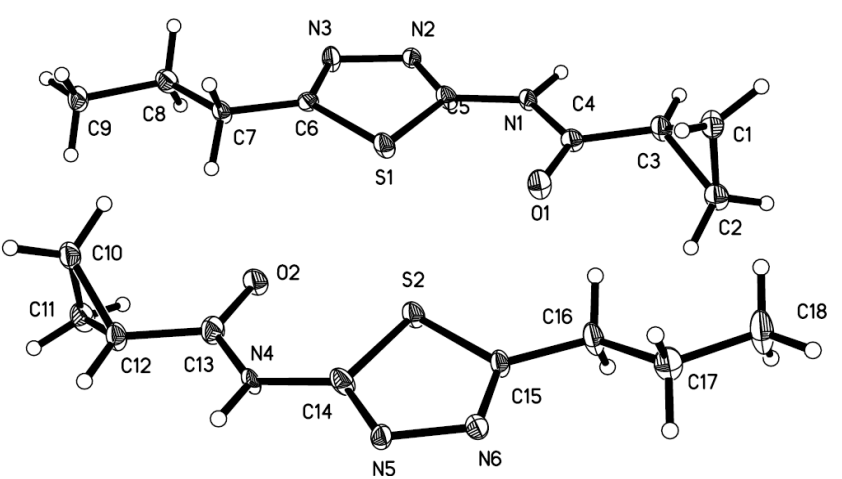

Fig. 1. Molecular structure of the title compound, showing displacement ellipsoids drawn at the $30 \%$ probability level

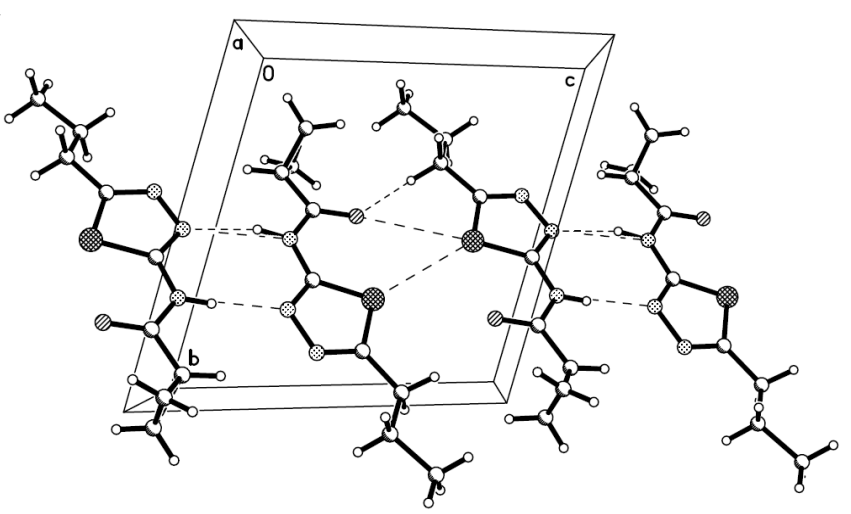

Fig. 2. Pack of title compound

Generally, the average bond lengths and bond angles of ring system (1,2,4-thiadiazole) are normal ranges. However, the $\mathrm{C} 5=\mathrm{N} 2$ bond $[1.295(6) \AA]$ and $\mathrm{C} 6=\mathrm{N} 3$ bond [1.307(6) $\AA]$ are similar with the general $\mathrm{C}=\mathrm{N}$ double bond length of $1.27 \AA^{21-23}$. The amide bond are normal, which is similar with the reported references ${ }^{24-27}$. As shown in Fig. 1, the 1,2,3thiadiazole ring $(\mathrm{N} 2, \mathrm{~N} 3, \mathrm{~S} 1, \mathrm{C} 5, \mathrm{C} 6)$ is fairly planar with mean deviation of $0.0035 \AA$. As shown in Fig. 2, intermolecular $\mathrm{N}-\mathrm{H} \cdots \mathrm{N}$ hydrogen bonds stabilize the solid-state structure. The 
title compound has an extensive network of hydrogen bonding involving the two acceptor atoms $\mathrm{N}$. In the bc plane, they are linked together by $\mathrm{N} 1-\mathrm{H} 1 \cdots \mathrm{N} 5, \mathrm{~N} 4-\mathrm{H} 4 \cdots \mathrm{N} 2$ hydrogen bonds. This hydrogen-bonding sequence is repeated to form a ring. The ring is shaped like a decagon and has two N1 atoms at the vertices, leading to a hydrogen-bond network defining cyclic motifs denoted $\mathrm{R}_{2}^{2}$ (6) (Table-3).

TABLE-3

HYDROGEN BOND LENGTHS $(\AA)$ AND BOND ANGLES $\left({ }^{\circ}\right)$

\begin{tabular}{lllll}
\hline $\mathrm{D}-\mathrm{H} \cdots \mathrm{A}$ & $\mathrm{d}(\mathrm{D}-\mathrm{H})$ & $\mathrm{d}(\mathrm{H} \cdots \mathrm{A})$ & $\mathrm{d}(\mathrm{D} \cdots \mathrm{A})$ & $\angle \mathrm{DHA}$ \\
\hline $\mathrm{N}(1)-\mathrm{H}(1) \ldots \mathrm{N}(5) \# 1$ & $0.904(10)$ & $2.03(2)$ & $2.896(6)$ & $160(5)$ \\
$\mathrm{N}(4)-\mathrm{H}(4) \ldots \mathrm{N}(2) \# 2$ & $0.894(10)$ & $2.019(13)$ & $2.909(5)$ & $174(4)$
\end{tabular}

Symmetry transformations used to generate equivalent atoms: \#1 $\mathrm{x}, \mathrm{y}$, $\mathrm{z}+1$ \#2 $\mathrm{x}, \mathrm{y}, \mathrm{z}-1$

\section{ACKNOWLEDGEMENTS}

The project was supported by the Program of National Natural Science Foundation of China (21102131). Thanks are also due to Dr. Liu for the crystal elucidation and culture.

\section{REFERENCES}

1. X.H. Liu, C.X. Tan and J.Q. Weng, Phosphorus Sulfur Silicon Rel Elem., 186, 552 (2011).

2. X.H. Liu, C.X. Tan and J.Q. Weng, Phosphorus Sulfur Silicon Rel. Elem., 186, 558 (2011).

3. X.F. Liu and X.H. Liu, Acta Cryst., E67, o202 (2011).

4. X.H. Liu, L. Pan, J.Q. Weng, C.X. Tan, Y.H. Li, B.L. Wang and Z.M. Li, Mol. Divers, 16, 251 (2012).

5. X.H. Liu, C.X. Tan and J.Q. Weng, Asian J. Chem., 23, 4064 (2011).

6. X.H. Liu, W.G. Zhao, B.L. Wang and Z.M. Li, Res. Chem. Intermed. 38, 1999 (2012).
7. M.S. Bashandy, Asian J. Chem., 23, 3191 (2011).

8. D.N. Sarkandi, L. Firoozpour, A. Asadipour, V. Sheibani, M.A.M. Asli, A. Davood, A. Shafiee and A. Foroumadi, Asian J. Chem., 23, 2503 (2011).

9. D.J. Li, Heterocycl. Commun., 15, 285 (2011)

10. M.N. Noolvi, H.M. Patel, N. Singh, A.K. Gadad, S.S. Cameotra and A. Badiger, Eur. J. Med. Chem., 46, 4411 (2011).

11. S.A. Carvalho, E.F. da Silva, M.C.S. Lourenco, M.V.N. de Souza and C.A.M. Fraga, Lett. Drug Des. Discov., 7, 606 (2010).

12. A. Saha, R. Kumar, R. Kumar and C. Devakumar, J. Heterocycl. Chem., 47, 838 (2010).

13. X.H. Liu, Y.X. Shi, Y. Ma, C.Y. Zhang, W.L. Dong, P. Li, B.L. Wang, B.J. Li and Z.M. Li, Eur. J. Med. Chem., 44, 2782 (2009).

14. X.H. Liu, L. Pan, Y. Ma, J.Q. Weng, C.X. Tan, Y.H. Li, Y.X. Shi, B.J. Li, Z.M. Li and Y.G. Zhang, Chem. Biol. Drug Des., 78, 689 (2011).

15. X.H. Liu, P.Q. Chen, B.L. Wang, Y.H. Li and Z.M. Li, Bioorg. Med. Chem. Lett., 17, 3784 (2007).

16. C.X. Tan, Y.X. Shi, J.Q. Weng, X.H. Liu, B.J. Li and W.G. Zhao, Lett. Drug Des. Discov., 9, 431 (2012).

17. C.X. Tan, J.Q. Weng, Z.X. Liu, X.H. Liu and W.G. Zhao, Phosphorus Sulfur Silicon Relat. Elem., 187, 990 (2012).

18. X.H. Liu, J.Q. Weng, C.X. Tan, L. Pan, B.L. Wang and Z.M. Li, Asian J. Chem., 23, 4031 (2011).

19. G.M. Sheldrick, SHELXS97 and SHELXL97, University of Göttingen, Germany (1997).

20. Wilson, A.J. International Table for X-ray Crystallograghy, vol. C, Kluwer Academic Publisher, Dordrecht, Tables 6.1.1.4 (500) and 4.2.6.8 (219) (1992)

21. X.H. Liu, L. Pan, C.X. Tan, J.Q. Weng, B.L. Wang and Z.M. Li, Pestic. Biochem. Physiol., 101, 143 (2011).

22. X.H. Liu, J.Q. Weng, C.X. Tan and H.J. Liu, Acta Cryst., E67, o493 (2011).

23. H.J. Liu, J.Q. Weng, C.X. Tan and X.H. Liu, Acta Cryst., E67, o1940 (2011).

24. Y.L. Xue, Y.G. Zhang and X.H. Liu, Asian J. Chem., 24, 3016 (2012).

25. Y.L. Xue, X.H. Liu and Y.G. Zhang, Asian J. Chem., 24, 1571 (2012).

26. P.Q. Chen, C.X. Tan, J.Q. Weng and X.H. Liu, Asian J. Chem., 24, 2808 (2012)

27. Y.L. Xue, Y.G. Zhang and X.H. Liu, Asian J. Chem., 24, 5087 (2012). 